\title{
GEOMETRIC CALIBRATION AND VALIDATION OF ULTRACAM AERIAL SENSORS
}

\author{
Michael Gruber, Bernhard Schachinger, Marc Muick, Christian Neuner, Helfried Tschemmernegg \\ Microsoft Ultra Cam Business Unit \\ Anzengrubergasse 8/4, 8010 Graz / Austria \\ \{michgrub, i-bescha, a-mamuic, Christian.Neuner, helfried.tschemmernegg\}@ microsoft.com
}

KEY WORDS: Photogrammetry, Digital camera, Calibration

\begin{abstract}
:
We present details of the calibration and validation procedure of UltraCam Aerial Camera systems. Results from the laboratory calibration and from validation flights are presented for both, the large format nadir cameras and the oblique cameras as well. Thus in this contribution we show results from the UltraCam Eagle and the UltraCam Falcon, both nadir mapping cameras, and the UltraCam Osprey, our oblique camera system. This sensor offers a mapping grade nadir component together with the four oblique camera heads. The geometric processing after the flight mission is being covered by the UltraMap software product. Thus we present details about the workflow as well. The first part consists of the initial post-processing which combines image information as well as camera parameters derived from the laboratory calibration. The second part, the traditional automated aerial triangulation (AAT) is the step from single images to blocks and enables an additional optimization process. We also present some special features of our software, which are designed to better support the operator to analyze large blocks of aerial images and to judge the quality of the photogrammetric set-up.
\end{abstract}

\section{INTRODUCTION}

The calibration procedure of the multiple head UltraCam digital aerial cameras was developed in 2003 and is continuously improved. This includes the recording of the temperature close to the CCD sensor arrays for every image taken with the camera and the improvement of the geometric processing of the images based on this information. Furthermore, also the temperature reading at the optical lens system was implemented, which now contributes to the stitching procedure. Post-processing of UltraCam images as well as the photogrammetric production chain are implemented in the UltraMap software product. In this contribution we show the new feature of UltraMap called "Visual Analytics", which allows to efficiently manage and control a large set of images. A fully three dimensional color coded presentation of the entire block and the adjusted orientation parameters of each image allow to detect deviations and errors in a very intuitive manner.

\subsection{UltraCam Eagle and Eagle Prime}

The flagship product of the UltraCam Sensor family is the UltraCam Eagle and since fall 2015 the Eagle Prime. Both cameras are based on the multiple cone concept which was already introduced in 2003. For geometric performance it is essential to understand this concept. The panchromatic subsystem exists of four independent camera heads with identical principal camera parameters. The backplanes of the four camera heads are equipped in total with 9 CCD sensor arrays which allow to seamlessly cover the rectangular footprint on the ground. The transformation of image content from each CCD detector array into a seamless frame image is based on the so-called stitching procedure.

\begin{tabular}{|l|l|l|l|}
\hline $\begin{array}{l}\text { PAN pixel } \\
\text { across }\end{array}$ & 23,010 & PAN focal length & $\begin{array}{l}80,100,120,210 \\
\mathrm{~mm}\end{array}$ \\
\hline $\begin{array}{l}\text { PAN pixel } \\
\text { along }\end{array}$ & 14,790 & $\mathrm{~b} / \mathrm{h}$ (f80, f100, f120, f210) & $\begin{array}{l}0.34 ; 0.27 ; 0.23 ; \\
0.13\end{array}$ \\
\hline $\begin{array}{l}\text { Max. } \\
\text { frame rate }\end{array}$ & $1.65 \mathrm{~s}$ & $\begin{array}{l}\text { AGL for } 5 \mathrm{~cm} \text { GSD } \\
\text { (f80, f100, f120, f210) }\end{array}$ & $\begin{array}{l}870 \mathrm{~m} ; 1,090 \mathrm{~m} ; \\
1,304 \mathrm{~m} ; 2,283 \mathrm{~m}\end{array}$ \\
\hline $\begin{array}{l}\text { Pan- } \\
\text { sharpening } \\
\text { ratio }\end{array}$ & $1: 3$ & $\begin{array}{l}\text { Max. speed for 5cm/10cm } \\
\text { GSD @ 80\% frontlap }\end{array}$ & $159 \mathrm{kts} / 318 \mathrm{kts}$ \\
\hline $\begin{array}{l}\text { FMC } \\
\text { mechanical, } \\
\text { TDI }\end{array}$ & $\begin{array}{l}\text { Max. speed for 5cm/10cm } \\
\text { GSD } 60 \% \text { frontlap }\end{array}$ & $318 \mathrm{kts} / 637 \mathrm{kts}$ \\
\hline $\begin{array}{l}\text { Lens } \\
\text { system }\end{array}$ & $\begin{array}{l}\text { Exchangeable } \\
\text { calibration }\end{array}$ & $\begin{array}{l}\text { Max. frontlap for } 5 \mathrm{~cm} / 10 \mathrm{~cm} \\
\text { GSD @ 140 kts }\end{array}$ & $82 \% / 91 \%$ \\
\hline
\end{tabular}

Tab. 1: UltraCam Eagle Prime Key Camera Parameters

\subsection{UltraCam Osprey Prime II}

UltraCam Osprey Prime II is the successor of the UltraCam Osprey Prime and is based on the same design concept consisting of a dual head panchromatic nadir component, single head RGB-color and near infrared nadir components complemented by a 4 direction RGB-color oblique component. The UltraCam Osprey Prime II is equipped with CCD sensor arrays with a pixel size of $5.2 \mu \mathrm{m}$. The panchromatic nadir image compiled from two single CCD camera heads is the geometry backbone of the camera. The investigation results presented hereinafter are derived solely from this nadir image. 


\begin{tabular}{|c|c|c|c|}
\hline $\begin{array}{l}\text { PAN nadir } \\
\text { image } \\
\text { (pixel) }\end{array}$ & $13,470 * 8,670$ & $\begin{array}{l}\text { Oblique RBG image } \\
\text { (pixel) }\end{array}$ & $10,300 * 7,700$ \\
\hline $\begin{array}{l}\text { PAN nadir } \\
\text { focal } \\
\text { length }\end{array}$ & $80 \mathrm{~mm}$ & $\begin{array}{l}\text { Oblique RGB focal } \\
\text { length }\end{array}$ & $120 \mathrm{~mm}$ \\
\hline $\begin{array}{l}\text { PAN nadir } \\
\text { CCD pixel } \\
\text { size }\end{array}$ & $5.2 \mu \mathrm{m}$ & $\begin{array}{l}\text { Oblique RGB pixel size } \\
\text { on CCD }\end{array}$ & $5.2 \mu \mathrm{m}$ \\
\hline $\begin{array}{l}\text { Nadir } \\
\text { RGB } \\
\end{array}$ & $6,735 \times 4,335$ & Oblique cones tilt & 45 degree \\
\hline Nadir NIR & $7,613 \times 4,900$ & $\begin{array}{l}\text { Oblique GSD (at } 5 \mathrm{~cm} \\
\text { nadir) }\end{array}$ & $5 \mathrm{~cm}$ \\
\hline $\begin{array}{l}\text { Pan- } \\
\text { sharpening } \\
\text { ratio }\end{array}$ & $1: 2$ & TDI (all cones) & $\begin{array}{l}\text { Non mechanical, } \\
\text { TDI }\end{array}$ \\
\hline $\begin{array}{l}\text { Max. } \\
\text { frame rate }\end{array}$ & $1.75 \mathrm{~s}$ & $\begin{array}{l}\text { Max. speed for } \\
5 \mathrm{~cm} / 10 \mathrm{~cm} \text { GSD @ 80\% } \\
\text { frontlap }\end{array}$ & $72 \mathrm{kts} / 146 \mathrm{kts}$ \\
\hline $\begin{array}{l}\text { AGL for } \\
5 \mathrm{~cm} \text { GSD } \\
\text { nadir } \\
\end{array}$ & $770 \mathrm{~m}$ & $\begin{array}{l}\text { Max. frontlap for } \\
5 \mathrm{~cm} / 10 \mathrm{~cm} \text { GSD @ } 140 \\
\text { kts }\end{array}$ & $62 \% / 81 \%$ \\
\hline
\end{tabular}

Tab 2: UltraCam Osprey Prime II Key Camera Parameters

\subsection{Temperature compensation per camera head}

Temperature reading from every lens cone and for each frame during operation is available for all UltraCam sensors of the $3^{\text {rd }}$ generation architecture which includes the cameras (Eagle, Falcon, Hawk and Osprey). All temperature readings of a production image are compared to the temperature readings from the laboratory calibration. These temperature differences are used within the stitching procedure.

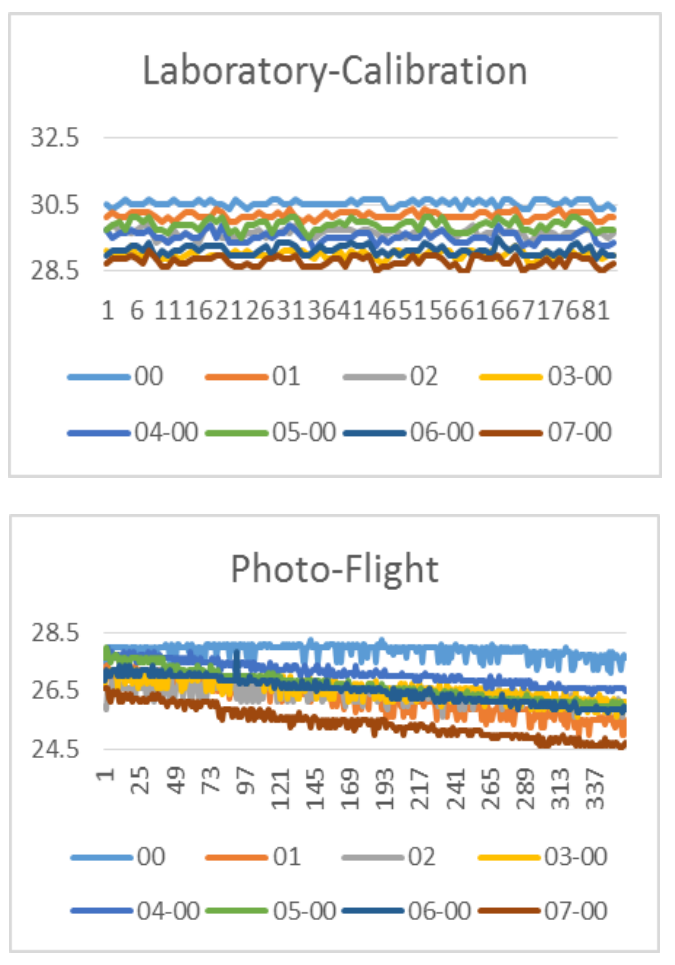

Fig 2: Temperature Readings from the UltraCam Eagle large format camera

\section{DIRECT SELF-CALIBRATION}

The improvement of results from aerial triangulation projects by means of self-calibration was already demonstrated and well accepted in the community. Special sets of parameters have been developed especially for UltraCam sensors and therefore are well aligned to the mechanical design of the camera system. Based on these parameters the post-processing is able to exploit information not only from one single frame but from a set of images or a complete aerial mission. Based on the practical experience and the knowledge from bundle adjustment projects with BINGO and its specific UltraCam parameters this information was introduced into the stitching procedure. Such a set of images is then introduced into the AAT process including automated tie point matching as well as manual interaction. The results from the least squares bundle adjustment shows the high quality of the UltraCam Images. Figure 3 illustrates the geometric quality of the images at the $<1 \mu \mathrm{m}$ level.
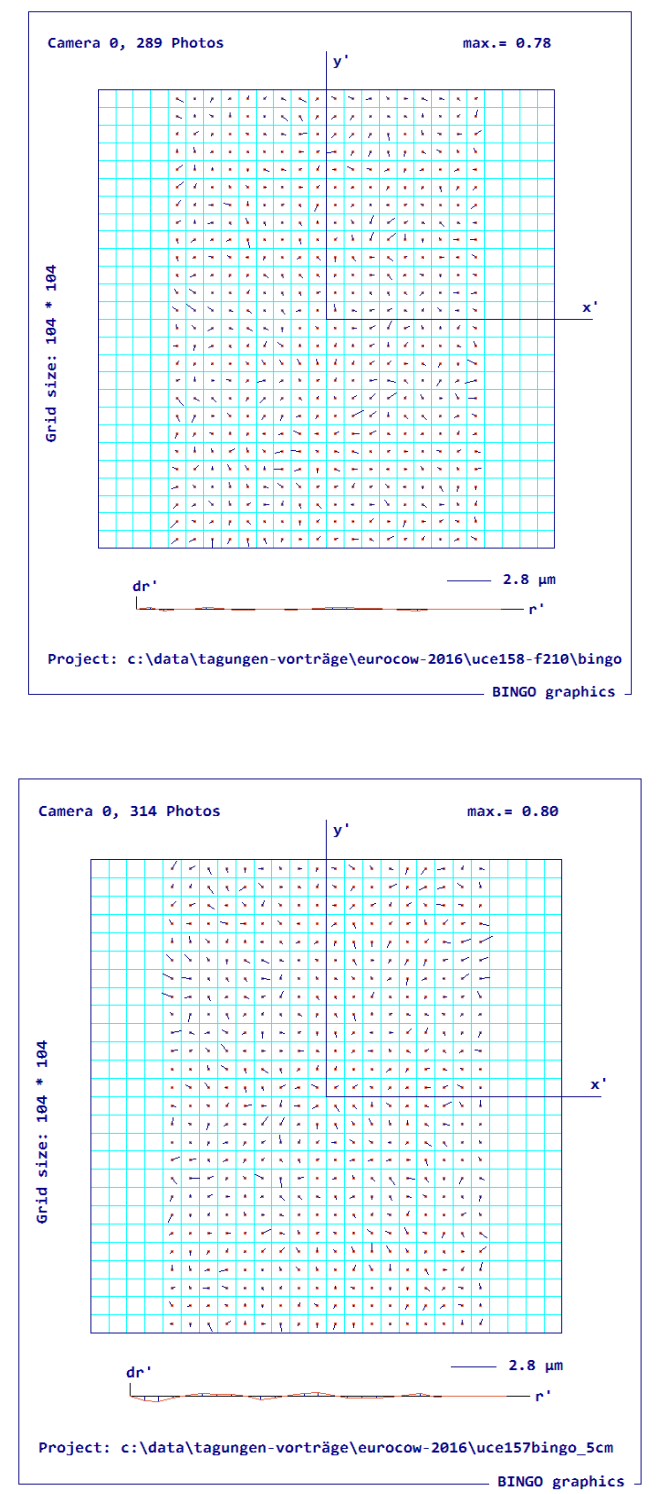

Fig.3: Image residual plot from an UltraCam Eagle f $210 \mathrm{~mm}$ flight mission (left) and an UltraCam Eagle $\mathrm{f} 100 \mathrm{~mm}$ focal lens (right). Maximum residuals are at $0.8 \mu \mathrm{m}$ level. 


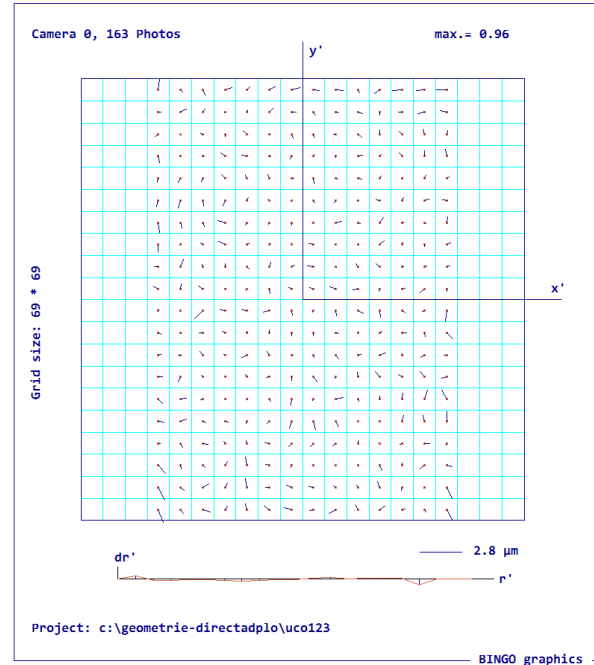

Fig.4: Image residual plot from an UltraCam Osprey flight mission (panchromatic nadir, $80 \mathrm{~mm}$ focal length) Maximum residuals are at $1 \mu \mathrm{m}$ level.

Figure 5 shows the normalized variance-components of photo measurements as function of photo radius as computed by BINGO and described in detail in Mélykuti B., Kruck E., 2015. The radius values are at 16, 23, 30, 34, 40, 46, 51 and $62 \mathrm{~mm}-$ similar for both UltraCam Eagle cameras - and each of the 8 image intervals contain a similar number of measured points (8700 points for UltraCam Eagle f 210 and 10700 points for UltraCam Eagle f 100). Radius values for the UltraCam Osprey sensor are smaller $(10,15,1922,2330,34$ and $42 \mathrm{~mm})$ and 4800 points are measured within each interval. The result of this investigation shows that central part of the image and the corner areas differ only at about $10 \%$.

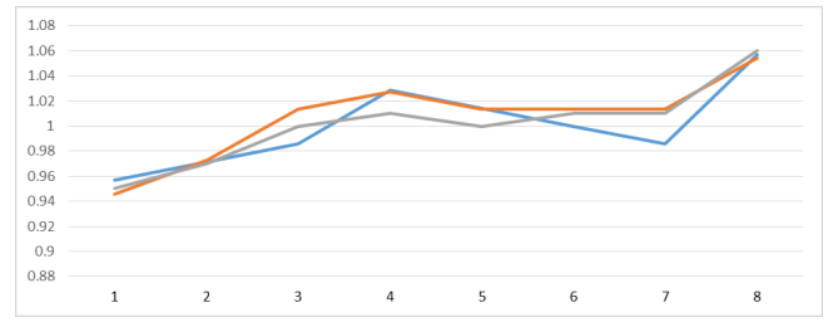

Fig. 5: A-posteriori normalized variance-components of photo measurements as function of photo radius from an UltraCam Eagle f $210 \mathrm{~mm}$ flight mission (blue) and an UltraCam Eagle $\mathrm{f}$ $100 \mathrm{~mm}$ focal lens (red). Values are between 0.95 and 1.06. The grey line represents data from UltraCam Osprey.

\section{ULTRAMAP - VISUAL ANALYTICS - MANAGING LARGE BLOCKS OF IMAGES}

During the last few years the size of aerial photo missions did continuously increase and thus new and intuitive methods to manage and control such large blocks of images became necessary. The UltraMap software system offers such tools based on a fully three dimensional and interactive graphical user interface.

Figure 6 shows a block of images from different flight missions. Colors are used to identify sub-blocks from one flight day. Results from the least squares adjustment allow to mark up those images which are out of specification or show larger deviation within orientation parameters.
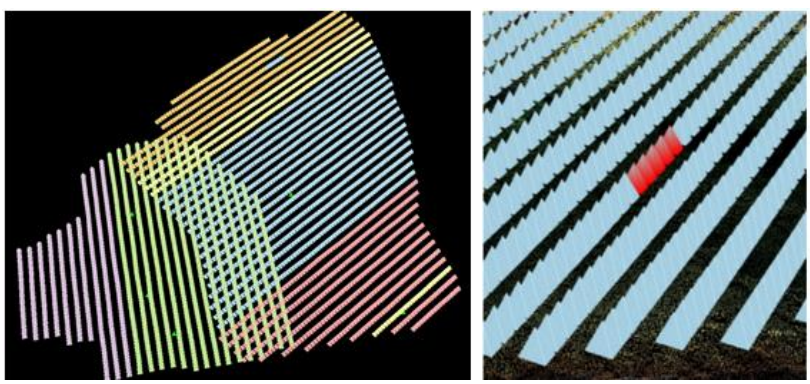

Fig. 6: Visualization of larger blocks: Colors separate subblocks (left) and mark up weak parameters (right)

\section{CONCLUSION}

In this contribution we have presented details from the calibration of the UltraCam Sensor products and improvements in the post-processing. We have shown the high quality of the result and thus the high geometry performance of our multi head camera product. In addition to the sensor and the processing chain of aerial images we illustrated details about our UltraMap Graphical User Interface and the concept of visual analytics.

\section{REFERENCES}

Mélykuti B., Kruck E., 2015: Geometric Accuracy Test of the newest large format Digital Aerial Survey Cameras, Proceedings of the American Society for Photogrammetry \& Remote Sensing, 4-8 May 2015, Tampa, FL.

Reitinger, B., Hoefler, M., Lengauer, A., Tomasi, R., Lamperter, M., Gruber, M., 2008: Dragonfly - Interactive Visualization of Huge Aerial Image Datasets. International Archives of Photogrammetry, Remote Sensing and Spatial Information Science, 31st Congress in Beijing, CN.

Reitinger, B., Gruber, M., 2013: UltraMap - Details and results from the digital photogrammetric workflow, Proceedings of the American Society for Photogrammetry \& Remote Sensing, 2529 March, 2013, Baltimore, MD.

Wiechert, A., Gruber, M., 2013: News from the UltraCam camera line-up, Proceedings of the American Society for Photogrammetry \& Remote Sensing, 25-29 March 2013, Baltimore, MD

Wiechert, A., Gruber, M., 2015: UltraCam and UltraMap - An Update, Proceedings of the 55th Photogrammetric Week, 7-11 September 2015, Stuttgart, GE. 